\title{
Artículo especial: Obras maestras del arte universal y la medicina: Noche transfigurada de Arnold Schönberg (1874-1951)
}

Universal art masterpieces and medicine: transfigured night by Arnold Schönberg (1874-1951)

Carlos Musso

Musso C. Obras maestras del arte universal y la medicina: Noche transfigurada de Arnold Schönberg (1874-1951). Evid Act Pract Ambul. 2016;19(3):92.

\section{Descripción de la obra}

Se trata de una pieza musical inspirada en el poema de Richard Dehmel, con el cual guarda un estrecho paralelismo: En un bosque de robles y bajo una luna resplandeciente, una mujer profundamente enamorada de un hombre al que recientemente ha conocido, le confiesa con dolor que espera un hijo de un extraño. El hombre, influenciado por el resplandor lunar que los atraviesa, le pide que no se mortifique, pues esa luz mágica que los inunda trasfigurará al niño haciéndolo de ambos.

Describimos a continuación la estrofa del poema de Dehmel y la transcripción del pasaje correspondiente de la obra musical.

\section{Estrofas del poema de Dehmel}

... una calidez singular pasa vibrante de ti a mí, de mí a ti.

Ella transfigurará al hijo del otro, para mí, por mí tú lo traerás al mundo. Me has penetrado de esplendor, de mí has hecho un niño..."

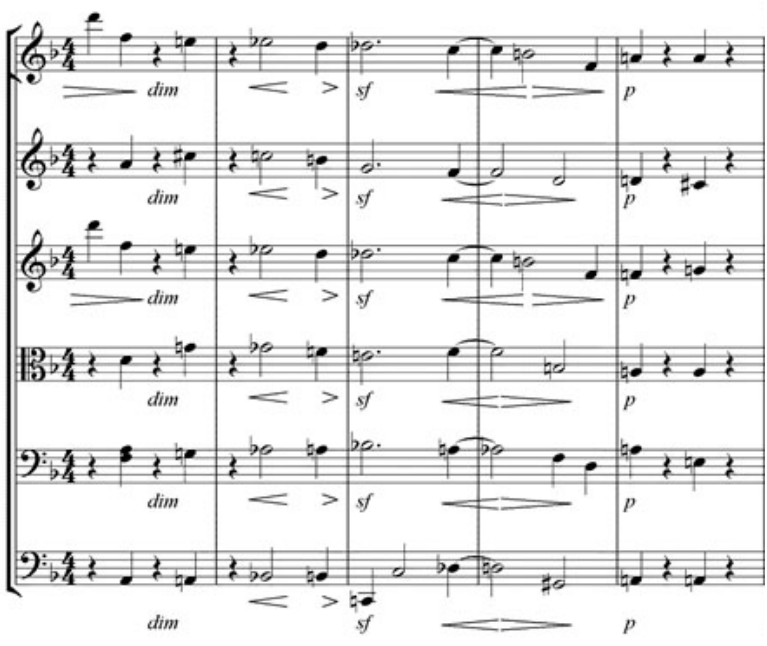

Schönberg y la transfiguración de la música occidental De la misma manera, que en el poema de Dehmel, la luz transfigura la identidad del niño por nacer; Schönberg transfiguró con la luz de su creatividad a la música occidental, al conseguir superar la ley de la tonalidad. A diferencia de la música tonal (la inmensa mayoría de la música que todos escuchamos) que se estructura en torno a una tonalidad conductora (música tonal), en la creación schoenbergiana no hay un tono predominante sino que toda la composición se estructura en múltiples tonos que se suceden sin que ninguno sea el principal (música atonal).

\section{La atonalidad y el fin de una perspectiva jerárquica}

Dado que nuestra perspectiva sobre los hechos es siempre limitada, toda interpretación que hagamos sobre ellos se estructura determinando arbitrariamente cuál de sus componentes es el central y cuál el periférico, de modo que toda interpretación monocorde, lo es más como consecuencia de nuestra limitación interpretativa, que como reflejo de la naturaleza de las cosas.

Jacques Derrida (de-contruccionismo) hizo hincapié en la absoluta arbitrariedad del ordenamiento conceptual de toda perspectiva clásica, e invitó a la obtención de nuevas interpretaciones a partir de la re-estructuración de las convenciones, a través de la jerarquización de los aspectos que éstas han relegado. No obstante, desde el de-construccionismo, a pesar de su perspectiva innovadora, se sigue diferenciando entre lo central y lo periférico. En este sentido, una concepción realmente superadora, fue aportada por el músico Arnold Schönberg con su creación de la música atonal, cuya composición se basa en el idea de que ningún tono predomine sobre los otros, en una perspectiva libre de jerarquías (similar a la adoptada por el cubismo de Pablo Picasso), en una estructura sin centro ni periferia, o mejor dicho donde cada componente es un pequeño centro entre muchos, y por ende una perspectiva en absoluta sintonía con lo real más allá de lo evidente, es decir con el mismísimo mundo de los elementos, de donde surge la materia y donde cada átomo resulta vital para la conformación del todo. En el ámbito médico asistencial, esta perspectiva múltiple es la que justifica la importancia de los espacios compartidos de diálogo (ateneos) y de trabajo (equipos) interdisciplinarios, donde todas las perspectivas son igual de valiosas, y que redundan en una labor mucho más enriquecedora tanto para pacientes como para terapeutas.

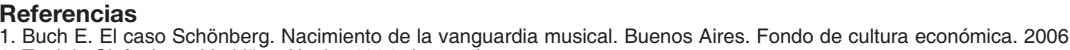

2. Tapiola Sinfonietta. Verklärte Nacht. 1994. (opus 4)

3. Derrida J. De la gramatología. Buenos Aires. Siglo veintiuno. 2003
} 